\title{
Multi-sensor monitoring for temperature stress evaluation of broccoli (Brassica oleracea var. italica)
}

\author{
Seung-Ju Cha ${ }^{1}$ Hyun Jun Park ${ }^{2} \cdot$ Joo-Kyung Lee $^{1} \cdot$ Seon-Ju Kwon ${ }^{1} \cdot$ \\ Hyo-Kyung Jee ${ }^{1} \cdot$ Hyun Baek ${ }^{1} \cdot$ Han-Na Kim ${ }^{1} \cdot J_{i n}$ Hee Park ${ }^{1}$

\section{브로콜리(Brassica oleracea var. italica)의 온도 스트레스 평가를 위한 다중 센서 모니터링}

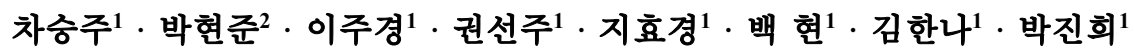

Received: 10 September 2020 / Accepted: 21 October 2020 / Published Online: 31 December 2020

(C) The Korean Society for Applied Biological Chemistry 2020

\begin{abstract}
Several sensors have been developed for soil and plants to assess plant stress due to climate change. Therefore, the objective of the study is to nondestructively evaluate temperature stress on plant by monitoring climatic and soil conditions and plant responses using various sensors. Plant responses were monitored by electrical conductivity in plant stem and sap flow rate. Electrical conductivity in plant stem reflects the physiological activity of plants including water and ion transport. Fully grown Brassica oleracea var. italica was exposed to $20 / 15^{\circ} \mathrm{C}$ (day/night) with $16 \mathrm{~h}$ photoperiods as a control, low temperature $15 / 10^{\circ} \mathrm{C}$, and high temperature $35 / 30{ }^{\circ} \mathrm{C}$ while climatic, soil, and plant conditions were monitored. Electrical conductivity in plant stem and sap flow rate increased during the day and decreased at night. Under low temperature stress, electrical conductivity in plant stem of Brassica oleracea var. italica was lower than control while under high temperature stress, it was higher than control indicating that water and ion transport was affected. However, chlorophyll a
\end{abstract}

Jin Hee Park $(\triangle)$

E-mail: pjinh@chungbuk.ac.kr

${ }^{1}$ Department of Agricultural Chemistry, Chungbuk University, Cheongju 28644, Republic of Korea

${ }^{2}$ Soil Research Institute, Prumbio Co. LTD, Republic of Korea

This is an Open Access article distributed under the terms of the Creative Commons Attribution Non-Commercial License (http://creativecommons. org/licenses/by-nc/3.0/) which permits unrestricted non-commercial use, distribution, and reproduction in any medium, provided the original work is properly cited. and $b$ increased in leaves subjected to low temperature stress and there was no significant difference between high temperature stressed leaves and control. Free proline contents in the leaves did not increase under low temperature stress, but increased under high temperature stress. Proline synthesis in plant is a defense mechanism under environmental stress. Therefore, Brassica oleracea var. Italica appears to be more susceptible to high temperature stress than low temperature.

Keywords Chlorophyll - Electrical conductivity in plant stem · Proline $\cdot$ Sap flow rate $\cdot$ Soil water $\cdot$ Temperature stress

\section{서 론}

지구온난화로 인해 폭염, 폭우, 가뭄, 한파 등과 같은 기상이변 으로 인한 환경 스트레스는 세포 구조를 파괴하고 주요 생리 기능을 손상시킬 수 있기 때문에 식물 성장에 영향을 미쳐, 작 물 수확량의 감소로 이어질 수 있다[1,2]. 기상이변과 같은 비 생물적 스트레스로 인한 식물 반응의 증상에는 괴사, 내부줄기 괴사, 꽃 괴사, 잎 시들음, 나무껍질 분열, 과일 부패 및 반점 등이 포함된다[3]. 환경 스트레스를 받은 작물은 외부 증상이 즉시 나타나지 않으며 일반적으로 증상이 작물 외부에 나타날 때 치료하면 식물이 회복하기에는 너무 늦다. 따라서 식물의 생 리학적 상태를 파악하기 위해서는 다양한 분석방법을 통해 환 경 스트레스에 대한 식물의 반응을 비파괴적으로 실시간 측정 할 필요가 있다. 
온도 스트레스는 가뭄, 염분 스트레스와 동일하게 식물의 삼 투압 스트레스를 유발하여 팽압 손실을 야기할 수 있다. 온도 가 적합하지 않으면 단백질이 활동성을 잃거나 변성될 수 있고, 막이 무질서해질 수 있으며 활성산소(ROS)가 과도하게 생성되 어 산화적 손상으로 이어질 수 있다. 결과적으로 세포 구조의 손상, 대사 기능 장애 및 광합성 억제는 조기 노화, 생식능력 저하 및 성장 장애의 원인이 된다[2].

프롤린은 ROS 제거제, 삼투질 및 단백질의 구조를 안정화시 키는 분자 샤페론(chaperone) 역할을 하여 스트레스로 인한 손 상으로부터 세포를 보호한다[2]. 식물이 저온, 고온, 중금속, 가 뭄, 염분 또는 병원체에 의해 스트레스를 받으면 프롤린이 축 적될 수 있다. 따라서 프롤린 함량은 식물의 생리적 조건을 모 니터링하고 스트레스에 대한 식물의 저항성을 평가하는 데 유 용한 지표이다[4]. 그러나 이러한 분석은 오랜 시간이 걸리고 결과를 분석하기가 어려우며 식물의 파괴적인 샘플링을 필요로 한다. 또한 프롤린 분석은 샘플링한 시점의 식물 상태를 보여 주는데 제한되어있기 때문에 실용적이지 않다.

식물은 환경의 변화에 따라 반응하기 때문에 식물의 반응을 직접적으로 측정하지 않고 식물 생육 환경을 모니터링하여 식 물의 반응을 예측하는 방법들이 있다. 기후변화를 측정하기 위 해 조도, 온도 및 습도를 모니터링하며, 식물 뿌리가 있는 토양 수분의 상태를 모니터링하기 위해 토양 수분 장력계, Time Domain Reflectometry, 석고블럭 및 전기전도도 등의 방법을 사 용한다. 또한, 이온 선택성 전극과 같은 화학 센서로 토양에 존 재하는 영양 성분을 측정할 수 있다. 하지만, 이러한 환경 센서 는 식물 생체 정보를 직접 모니터링하는 것이 아니며 환경이 식물마다 미치는 영향력이 다르기 때문에 환경 센서만으로 식 물의 상태를 정확히 파악하는 것은 불가능하다[5]. 한정된 환경 계측 센서의 측정을 통해 식물의 상태를 정확하게 나타낼 수 없기 때문에 토양 조건 및 작물 생체 정보 센서의 추가 모니터 링을 통해 종합적으로 보는 것이 필요하다.

본 연구에서는 식물 줄기의 물이나 이온 수송을 반영하는 식 물의 내부 전기전도도(ECps)와 sap flow rate를 모니터링하여 온도 스트레스에 대한 식물의 생리학적 반응을 분석하였다. 식 물 세포의 전기적 특성은 성장 단계, 세포 구조, 영양소 및 물 과 온도와 관련된 조건에 따른 식물 생리학적 상태를 평가하는 데 사용될 수 있다[6]. 식물 줄기의 내부 전기전도도는 환경 조 건의 변화에 반응한다[7]. 따라서 식물의 내부 전기전도도를 모 니터링하면 스트레스를 받는 조건하에서 식물이 겪는 생리학적 변화를 이해하는 데 도움이 될 수 있다. Sap flow rate 계측은 농업, 원예, 임업 및 생태학에서 환경에 따른 식물의 수분 흡수 능력을 평가하는데 활용되고, sap flow rate 측정을 통해 경작 가능한 작물, 과수원, 산림 농장 및 자연 식생의 물 사용량을 정량화하고, 관수량을 결정하는데 활용한다[8]. 따라서 본 연구 에서는 식물 줄기 내부의 전기전도도와 sap flow rate를 측정하 면서 동시에 온도, 상대습도, 광합성유효광량자속 밀도 (Photosynthetic Photon Flux Density, PPFD), $\mathrm{CO}_{2}$ 등 식물 생육 기후조건을 모니터링하였고, 토양의 온도, 수분함량, 전기 전도도를 모니터링하여 토양 상태도 측정하였다. 이 연구의 목 적은 저온과 고온 스트레스 하에서 Brassica oleracea var. italica 의 생리적 반응을 조기에 발견하기 위해 식물 내부 전기전도도 를 포함한 다양한 센서의 적용 가능성을 평가하는 것이다.

\section{재료 및 방법}

\section{브로콜리의 생육 및 온도 스트레스 처리}

농경지에서 채취한 토양과 상업용 상토를 $1: 1 \mathrm{v} / \mathrm{v}$ 비율로 혼합 하고, 토양 살충제(Depucon, Farm Hannong) $4 \mathrm{~g} / \mathrm{kg}$ 을 혼합물에 첨가하였다. 모판에서 5 주간 자란 모종을 $3.6 \mathrm{~L}$ 화분에 $3 \mathrm{~kg}$ 의 혼합 토양을 넣고 이식하였다. Brassica oleracea var. italica 모종은 스트레스 조건에 노출되기 전 화뢰가 생길 때까지 6 주 간 온실 조건에서 생육하였으며, 생육 기간 동안 포장용수량 상 태로 관수하였다.

Brassica oleracea var italica는 생장상에서 상대습도 $60 \%$, 16 시간 광주기로 $20 / 15^{\circ} \mathrm{C}$ (주간/야간)에 4 일 동안 노출시켰으 며 이를 대조구로 하였다. 저온 처리의 경우, Brassica oleracea var. italica은 생장상에서 초기에는 대조구와 같은 조건에 4일간 노출시켰다가 이후 4 일 동안 상대습도 $60 \%, 16$ 시간 광주기로 $15 / 10^{\circ} \mathrm{C}$ (주간/야간)에 노출시켰다. 고온 처리의 경우, 다른 조 건은 바꾸지 않고 온도를 $35 / 30{ }^{\circ} \mathrm{C}$ (주간/야간)에 노출시켰다. 식물 반응(ECps, sap flow rate), 기후(온도, 상대습도, $\mathrm{CO}_{2}$ ), 토양 조건(토양 수분함량, 토양온도, 전기전도도)을 실험 기간 동안 모니터링하였다.

Brassica oleracea var. italica의 ECps, Sap flow rate, 기후, 토양 환경 모니터링

저온 및 고온 스트레스 하에서 Brassica oleracea var. italica의 생리학적 변화를 모니터링하기 위해, 생장상에서 식물이 온도 스트레스 조건에 노출되는 동안 Junsmeter II (Prumbio, Suwon, Korea)를 사용하여 ECps를 측정하였다. 3개의 스테인 리스 바늘이 달린 2 개의 전극을 Brassica oleracea var. italica 줄기의 양 측면에 삽입하였다. 두 전극에 전류를 공급한 후 브 리지 회로 방법을 사용하여 저항을 측정했다[7]. 전기 저항값은 데이터 로거(CR1000, Campbell Scientific, Logan, UT, USA) 를 사용하여 15 분마다 저장하였고, 수신된 데이터는 식 (1)에 따라 전기전도도로 변환하였다.

$$
\sigma=\frac{1}{R} \times \frac{L}{A}=\frac{1}{R} \times \frac{\pi r}{100}
$$

여기서 $\sigma(\mathrm{S} / \mathrm{m})$ 는 Brassica oleracea var. italica의 ECps, L은 측정된 Brassica oleracea var. italica 줄기 둘레의 절반 길이 $(\mathrm{mm})$ 이고, $\mathrm{R}$ 은 저항 $(\Omega)$ 이며, $\mathrm{A}$ 는 바늘이 삽입된 줄기의 단면 적 $\left(\mathrm{mm}^{2}\right), \mathrm{r}$ 은 Brassica oleracea var. italica 줄기의 반경 $(\mathrm{mm})$ 이다.

Sap flow rate (Telofarm, Seoul, Korea)는 식물 줄기에 센서 를 한 개씩 삽입하여 2분간격으로 측정하였다. 기후는 광합성 유효광량자속 밀도(LightScout, Spectrum Technologies, Aurora, $\mathrm{IL}, \mathrm{USA}), \mathrm{CO}_{2}$, 온도 및 상대습도를 측정하였다. 토양 조건은 각 화분마다 WaterScout SMEC 300 (Encosys, Anyang, Korea)으로 토양 수분함량 $(\% \mathrm{VWC})$, 토양온도 $\left({ }^{\circ} \mathrm{C}\right)$, 전기전도도 $(\mathrm{mS} / \mathrm{cm})$ 를 측정하였다.

\section{잎의 엽록소 함량 분석}

스트레스에 의한 엽록소 함량 변화를 평가하기 위해, 대조구, 저온 및 고온 처리 후에 Brassica oleracea var. italica 잎을 
무작위로 채취하였다. 채취한 잎을 증류수로 세척한 다음 작은 조각으로 분쇄하였다. 신선한 잎 $(\mathrm{FW}) 0.5 \mathrm{~g}$ 을 $50 \mathrm{~mL}$ 코니컬 튜 브에 넣고 $25 \mathrm{~mL}$ 의 $80 \%$ 아세톤을 첨가하였다. 코니컬 튜브를 흔들어 24시간 동안 암조건에 두었다. $0.45 \mu \mathrm{m}$ 실린지 필터로 여과한 후, UV/Vis 분광 광도계(Orion AquaMate 7000, Thermo-Fisher Scientific, Waltham, MA, USA)로 $80 \%$ 아세톤 을 blank로 하여 645 및 $665 \mathrm{~nm}$ 에서의 흡광도를 측정하였다. 식물 잎의 엽록소 $\mathrm{a}$ 및 $\mathrm{b}$ 함량은 Maclachlan 및 Zalik [9]의 방정식에 따라 계산하였다.

$$
\begin{gathered}
C_{a}=\frac{\left(12.3 D_{663}-0.86 D_{645}\right) \times V}{d \times 1000 \times W} \\
C_{b}=\frac{\left(19.3 D_{645}-3.60 D_{663}\right) \times V}{d \times 1000 \times W}
\end{gathered}
$$

$\mathrm{C}_{\mathrm{a}}$ 는 엽록소 $\mathrm{a}$ 함량 $(\mathrm{mg} / \mathrm{g} \mathrm{FW}), \mathrm{C}_{\mathrm{b}}$ 는 엽록소 $\mathrm{b}$ 함량 $(\mathrm{mg} / \mathrm{g}$ $\mathrm{FW}), \mathrm{D}$ 는 표시된 파장에서의 광밀도, $\mathrm{V}$ 는 최종 용액 부피 $(\mathrm{mL})$, $\mathrm{W}$ 는 신선한 잎의 무게 $(\mathrm{g}), \mathrm{d}$ 는 빛의 경로 $(\mathrm{cm})$ 이다.

\section{잎의 프롤린 함량 분석 및 식물 건조 중량 측정}

엽록소 분석과 동일한 방식으로 Brassica oleracea var. italica 잎을 채취하였다. 잎을 증류수로 세척하고 작은 조각으로 분쇄 했다. 프롤린 함량은 Bates et al. [10]이 제안한 acid-ninhydrin reagent $(2.5 \mathrm{~g}$ ninhydrin, $60 \mathrm{~mL}$ glacial acetic acid 및 $40 \mathrm{~mL}$ $6 \mathrm{M}$ phosphoric acid)으로 추출한 후 비색법을 사용하여 분석하 였다. $50 \mathrm{~mL}$ 코니컬 튜브에 $10 \mathrm{~mL} 3 \%$ sulfosalicylic acid와 $0.5 \mathrm{~g}$ 의 신선한 잎 $(\mathrm{FW})$ 을 혼합하고 초음파분산기에서 30 분 동 안 반응시켰다. 추출된 용액을 $25^{\circ} \mathrm{C}$ 에서 10 분 동안 $4000 \mathrm{rpm}$ 으로 원심 분리하고 $0.45 \mu \mathrm{m}$ 실린지 필터로 여과하였다. 여과 액 $2 \mathrm{~mL}$ 를 $2 \mathrm{~mL}$ 의 acid-ninhydrin reagent 및 $2 \mathrm{~mL}$ 의 glacial acetic acid와 혼합하고 $100{ }^{\circ} \mathrm{C}$ 에서 1 시간 동안 가열하였다. 얼 음물에서 샘플을 냉각시킨 후, $4 \mathrm{~mL}$ 의 톨루엔을 용액에 첨가하 고 20 초 동안 교반하였다. 발색단을 함유하는 톨루엔을 수성상 으로부터 분리하고 UV/Vis 분광 광도계를 사용하여 톨루엔을 blank로 하여 $520 \mathrm{~nm}$ 에서 흡광도를 측정하였다. 프롤린 농도는 표준 곡선 $(0-500 \mu \mathrm{g} / \mathrm{mL})$ 을 만든 후, 신선한 잎 중량을 기준으 로 계산하였다.

Brassica oleracea var. italica를 온도 스트레스 조건에 노출 시키고 식물 반응과 환경 조건을 모니터링 한 후 잎, 줄기, 뿌 리로 나누어 증류수로 세척한 다음 $60{ }^{\circ} \mathrm{C}$ 오븐에서 건조 후 중 량을 측정하였다.

\section{통계처리}

SPSS 소프트웨어(IBM, Armonk, NY, USA)를 사용하여 데이터 의 통계 분석을 수행하였다. 데이터는 일원배치 분산분석(Oneway ANOVA Analysis)을 이용하여 비교하였고 사후 분석은 Fisher's Least Significant Difference (LSD)로 시행하였다. 데 이터는 평균과 표준 편차로 표시하였다.

\section{결과 및 고찰}

\section{정상적인 생육 조건 하에서 Brassica oleracea var. italica의 반응}

Brassica oleracea var. italica를 저온 및 고온에 노출시키기 전 에, 정상적인 생육 조건 하에서 식물 반응(ECps, sap flow rate), 기후 조건(온도, 상대습도, 광합성유효광량자속 밀도, $\mathrm{CO}_{2}$ ) 및 토양 조건(토양온도, 토양 수분함량, 전기전도도)을 모니터링 하였다. 생장상의 설정 조건에 따라 낮에는 광합성유효광량자속 밀도, 대기 온도 및 토양 온도가 증가하였으며 상대습도는 밤 과 낮 모두 $60 \%$ 로 설정하였으나 밤에 약간 증가하는 경향을 보였으며 $\mathrm{CO}_{2}$ 도 밤에 증가하였으며 관수할 때 증가하였다. ECps 및 sap flow rate는 낮에 증산량이 증가하면서 식물체 내 수분 이동의 증가로 낮에는 증가하고 밤에는 감소하는 패턴을 보였다. 양분은 물과 함께 이동하기 때문에 $\mathrm{ECps}$ 는 수액 이동 이 증가하면서 증가하였다. 이전 연구에서 밤과 낮의 식물 줄 기의 이온을 추출해 분석한 결과 양이온과 음이온의 함량이 밤 보다 낮에 높은 것으로 나타났다[7]. 토양의 수분 및 전기전도 도 값은 관수를 하였을 때 급격히 증가하였다(Fig. 1).

정상적인 생육 조건의 Brassica oleracea var. italica에서 전 기전도도 및 sap flow rate는 상대습도 및 $\mathrm{CO}_{2}$ 와 음의 상관 관 계가 있다. 낮에는 기온이 높아져 포화 수증기량이 증가하여 상 대습도가 낮고, 기온이 낮은 밤에는 포화 수증기량이 감소하여 상대습도가 높다. $\mathrm{CO}_{2}$ 는 광이 있는 낮에 식물이 광합성을 하면 서 대기 중의 $\mathrm{CO}_{2}$ 를 사용하여 대기 중의 $\mathrm{CO}_{2}$ 함량을 감소시 킨다. 따라서, 상대습도와 $\mathrm{CO}_{2}$ 가 낮은 낮에는, 광에 의한 증산 속도가 증가하고 줄기를 통해서 물의 흐름인 sap flow rate가 증가한다[11]. 식물체 내부에 물이 이동하면서 이온도 같이 이 동하고 물과 이온의 수송이 증가함에 따라 이전 연구에서 낮에 Capsicum annuum의 내부 전기전도도가 증가함을 확인하였다 [7]. 반면에, 밤에는 온도와 광의 세기가 감소함에 따라, Brassica oleracea var. italica의 증산작용이 원활하지 않아 줄기의 ECps 와 sap flow rate가 감소하였다. 상대습도 및 온도, 광의 세기와 같은 정상적인 생육 조건에 반응하여 Brassica oleracea var. italica의 ECps와 sap flow rate는 매일 올라갔다 내려가는 패턴 을 보였다. ECps는 상대습도 및 온도, 광의 세기와 같은 기후 조건과 관련이 있어 이 패턴에서 $\mathrm{ECps}$ 의 편차는 식물 내에서 이상징후를 판단하는 기준이 될 수 있다[7].

\section{저온 스트레스 하에서 Brassica oleracea var. italica의 반웅}

상대습도 $60 \%, 16$ 시간 광주기로 정상 생육조건과 마찬가지로 상대습도와 광주기를 유지하면서 주간/야간의 온도조건을 $15 / 10$ ${ }^{\circ} \mathrm{C}$ 로 하여 저온 스트레스를 받은 Brassica oleracea var. italica 의 ECps와 sap flow rate는 대기 온도와 토양온도가 감소함에 따라 정상적인 생육 조건의 ECps와 sap flow rate 보다 값이 급격하게 감소했다(Fig. 2). Repo 등[12]은 저온 스트레스가 지 속되는 동안 식물의 줄기에서 세포 외 및 세포 내 저항이 증가 했다고 보고하였다. 저항은 전기전도도와 반비례하기 때문에 이 

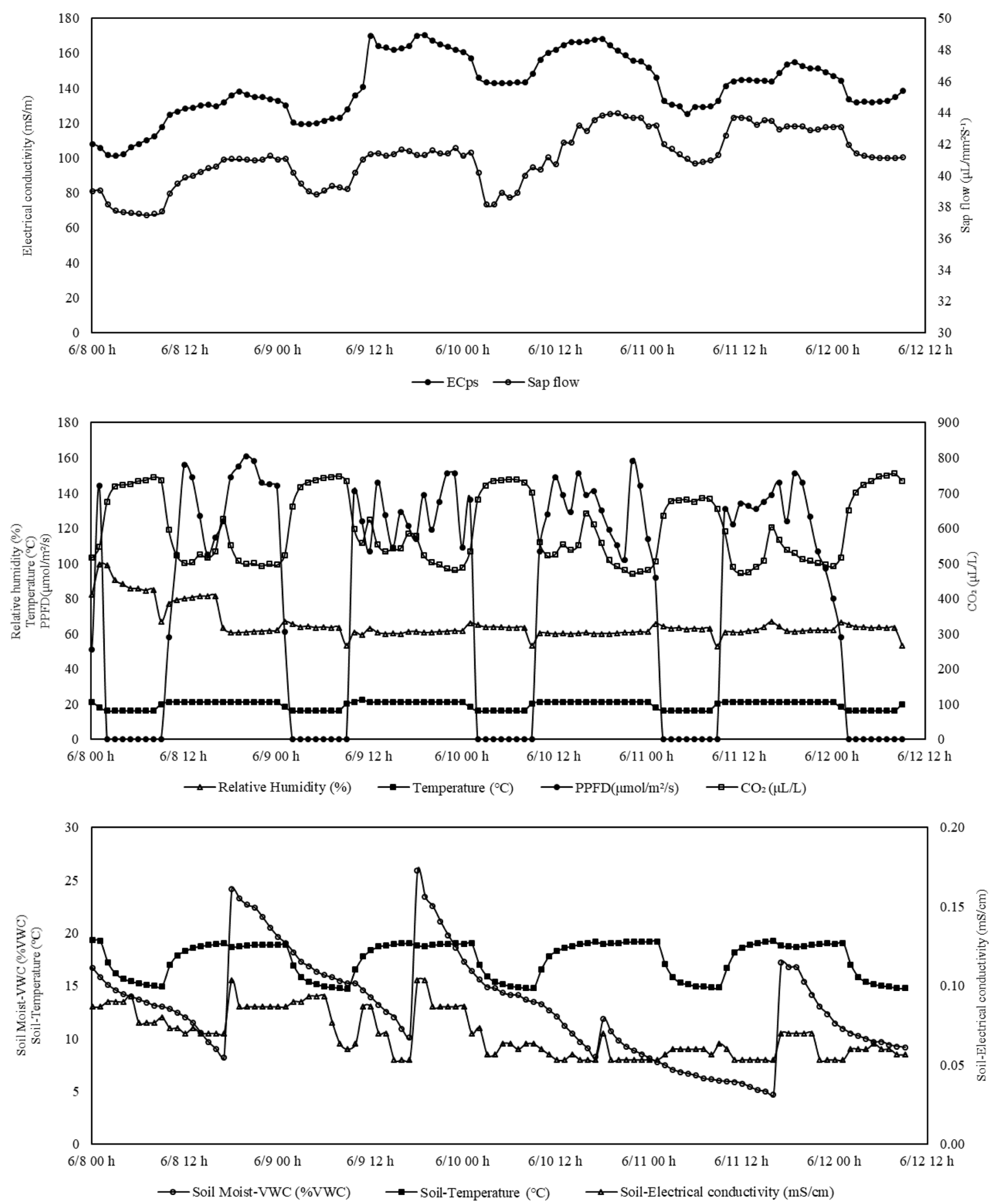

Fig. 1 Electrical conductivity in plant stem (ECps), sap flow rate, relative humidity, temperature, PPFD (photosynthetic photon flux density), $\mathrm{CO}_{2}$, soil water content and temperature, and soil electrical conductivity monitoring for control treatment $\left(20 / 15^{\circ} \mathrm{C}\right.$ day/night) 

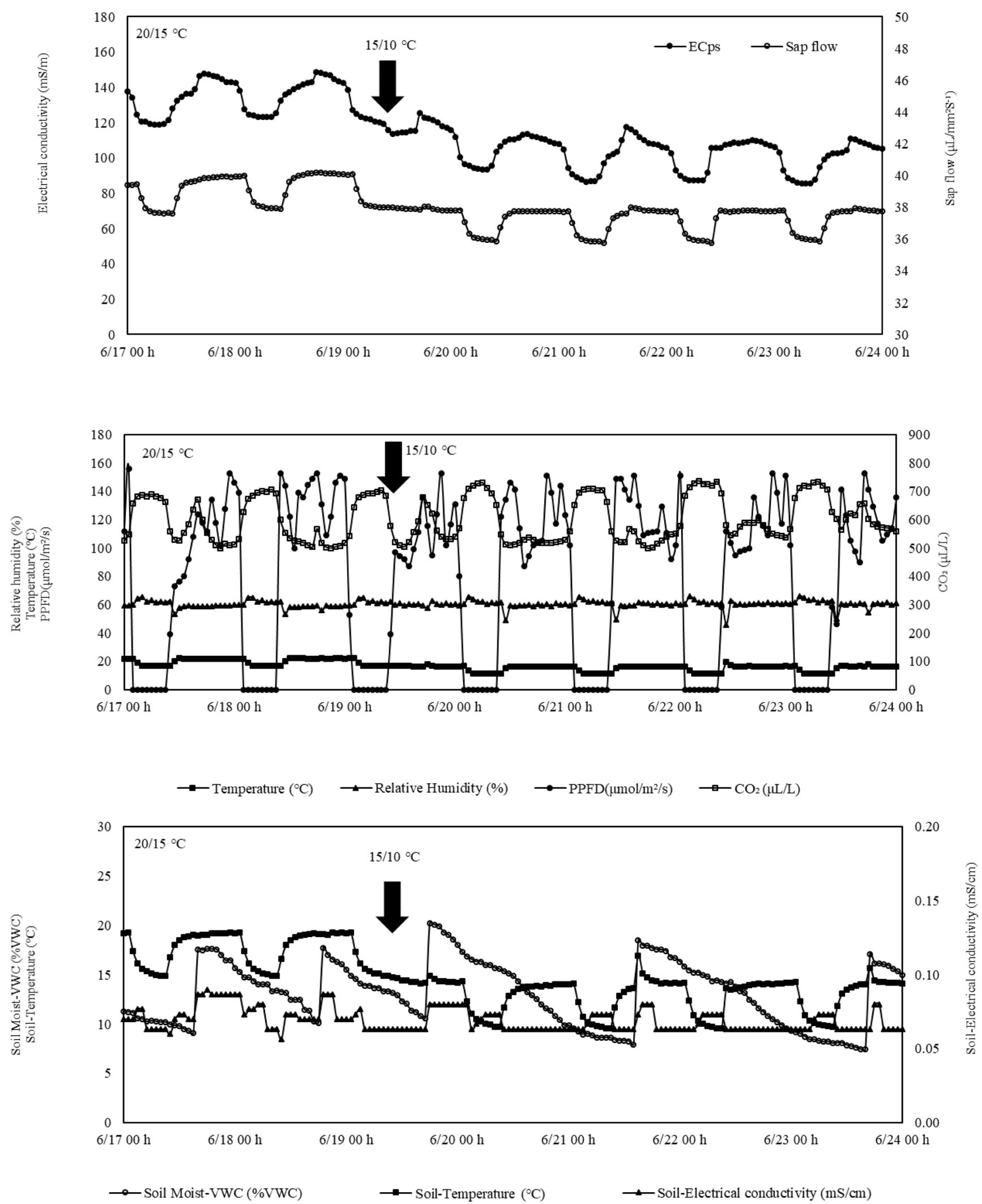

Fig. 2 Electrical conductivity in plant stem (ECps), sap flow rate, relative humidity, temperature, PPFD (photosynthetic photon flux density), $\mathrm{CO}_{2}$, soil water content and temperature, and soil electrical conductivity monitoring for low-temperature treatment $\left(15 / 10^{\circ} \mathrm{C}\right.$ day/night $)$ 

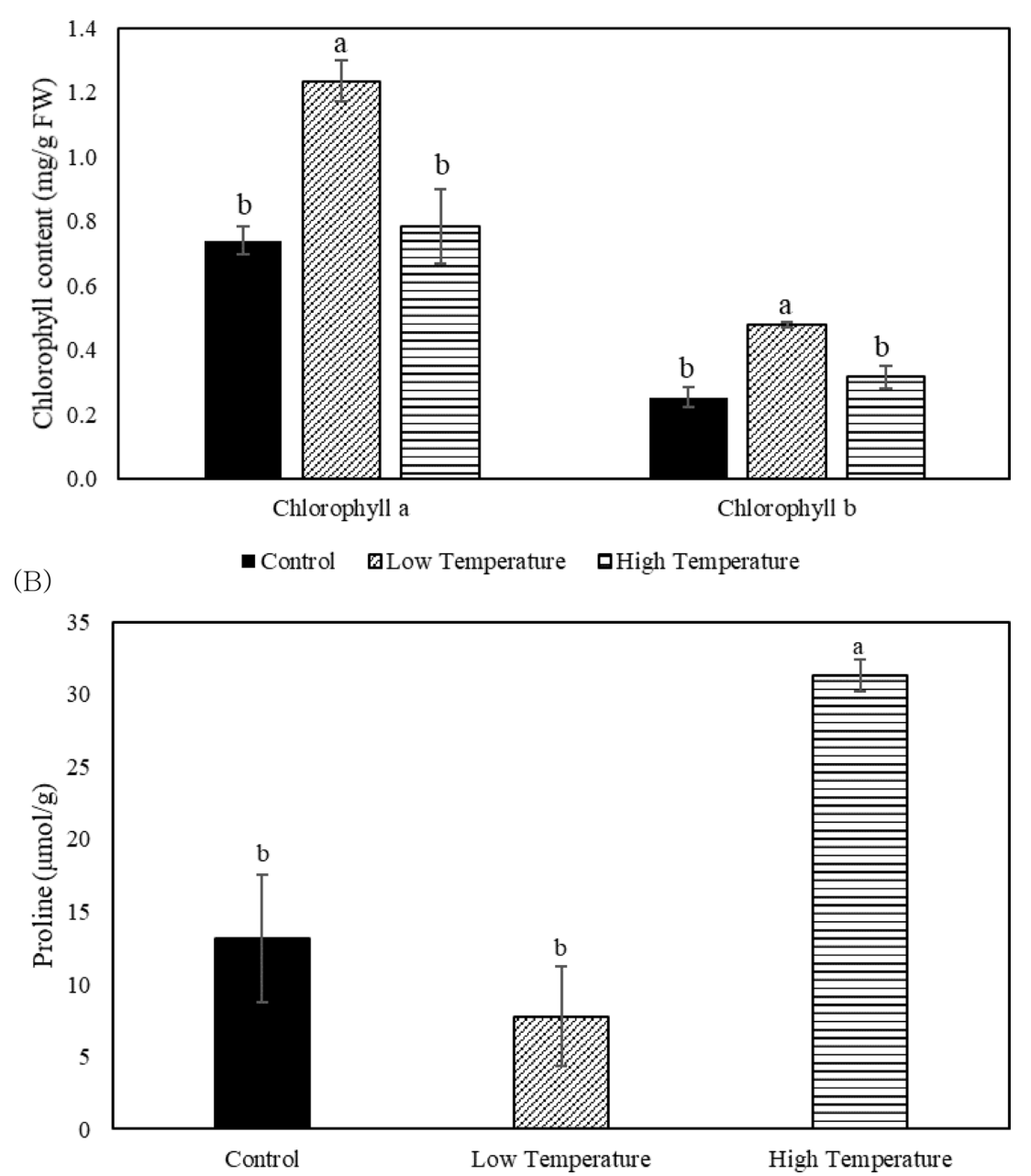

Fig. 3 Chlorophyll a and b contents (A) and proline concentrations (B) of Brassica oleracea var. italica leaves exposed to control, low-temperature and high-temperature treatment. Data are presented as mean \pm standard deviation and different letters above the bar indicate significant differences among treatment by one-way ANOVA followed by LSD test $(p<0.05)$

는 저온 스트레스 하에서 전기전도도가 감소함을 의미한다. 또 한, 저온 토양은 뿌리 성장, 영양소 및 수분의 흡수뿐만 아니라 광합성 및 기공 전도도를 감소시킨다. 가뭄 스트레스와 유사하 게, 저온 스트레스를 받은 Populus tremuloides의 뿌리는 수분 흡수를 억제하고 기공 전도도를 감소시켰다[13]. 따라서 수분 및 이온의 수송에 관련이 있는 $\mathrm{ECps}$ 와 sap flow rate가 저온 스트레스 조건에서 감소하였음을 알 수 있다. ECps, sap flow rate, 대기 온도와 토양 온도를 제외한 상대습도, $\mathrm{CO}_{2}$, 토양 수 분, 토양 전기전도도는 정상적인 생육 조건 하에서의 상태와 큰 변화가 없었으며, 토양 수분 및 토양 전기전도도 값은 관수를 하였을 때 급격히 증가하였다(Fig. 2).

저온 스트레스하에서 Brassica oleracea var. italica 잎의 엽 록소 $\mathrm{a}$ 및 $\mathrm{b}$ 함량은 정상적인 생육 조건에서 자란 엽록소 함량 보다 높게 나타났으며 유의한 차이가 있었다(Fig. 3A). 일반적 으로 저온 조건에서는 엽록소 생합성이 감소하기 때문에 저온 스트레스에서는 식물 잎의 엽록소 함량이 감소한다[14]. 그러나 본 연구에서는 저온 스트레스하에서 엽록소 함량이 증가하였다. Markhart et al. [15]에 따르면 Brassica oleracea var. italica은
저온에 저항성이 있기 때문에 저온조건에서 스트레스를 받지 않 은 것으로 판단된다. 저온 스트레스 조건에서 Brassica oleracea var. italica의 프롤린 함량은 정상적인 생육 조건에서 자란 잎 의 프롤린 함량과 비교하여 유의한 차이가 없었다(Fig. 3B). 일 반적으로 식물이 생물학적 또는 비생물학적인 스트레스를 받으 면 프롤린 함량이 증가할 수 있다. 프롤린의 축적은 식물이 저 온 스트레스 상태에 견딜 수 있게 해주며 이는 스트레스 반응 과 상관 관계가 있다[16]. 저온 조건에서 프롤린은 저온 손상에 대한 반응으로 Hordeum distichum L., Malus sylvestris 및 Triticum aestivum L.의 잎에 축적되었다[17,18]. 본 연구에서 저 온 스트레스 조건에서 프롤린의 함량이 증가하지 않은 것은 엽 록소 함량이 증가한 것과 마찬가지로 Brassica oleracea var. italica가 저온스트레스를 받지 않았다는 것을 보여준다. 저온 스 트레스를 받은 Brassica oleracea var. italica의 건물중은 잎, 줄기, 뿌리 모두 유의한 차이가 없었다(Table 1). 따라서, 저온 스트레스하에서 엽록소와 프롤린 함량 및 건물중을 대조구와 비 교해보면 Brassica oleracea var. italica는 저온에 스트레스를 받지 않은 것으로 판단된다. 

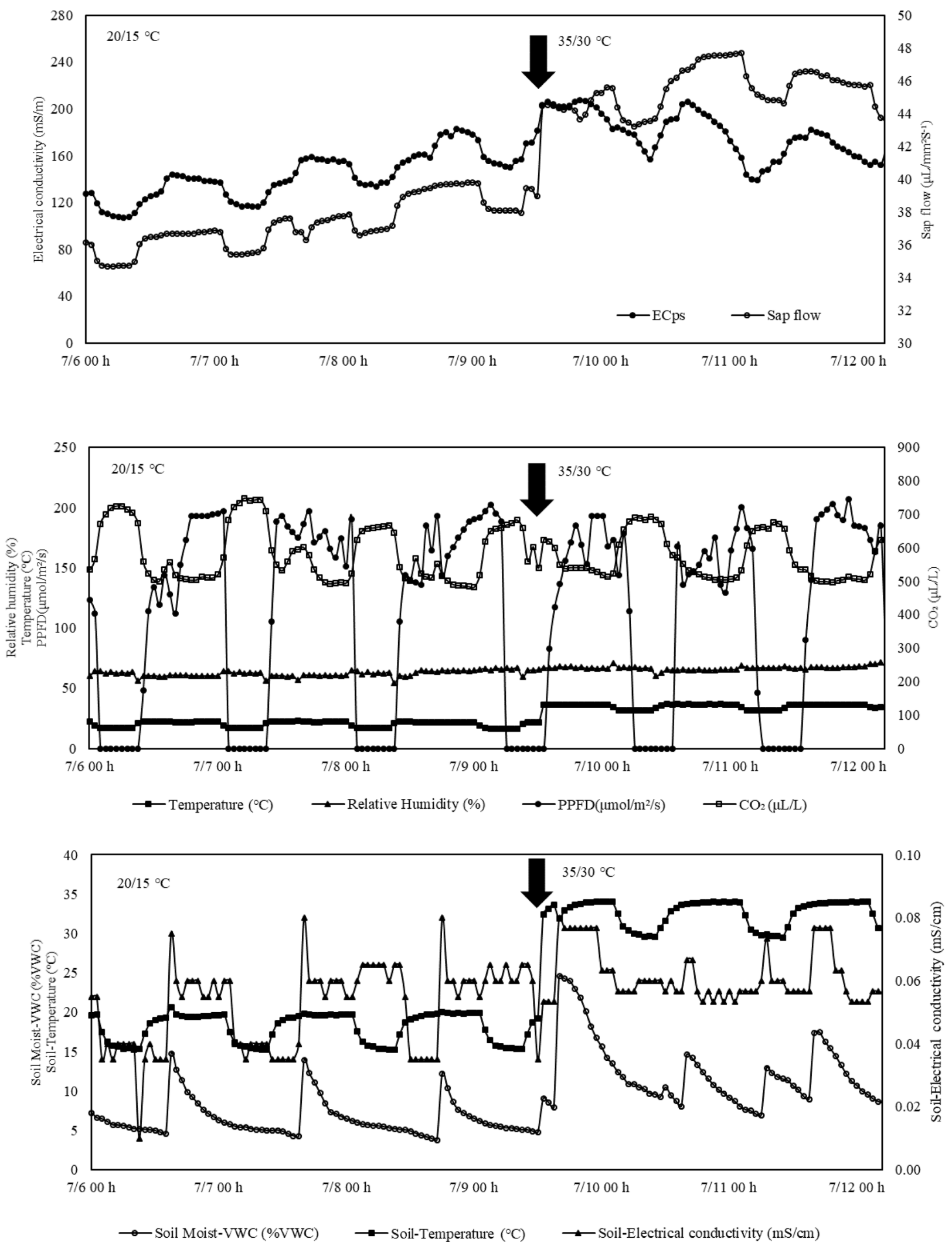

Fig. 4 Electrical conductivity in plant stem (ECps), sap flow rate, relative humidity, temperature, PPFD (photosynthetic photon flux density), $\mathrm{CO}_{2}$, soil water content and temperature, and soil electrical conductivity monitoring for high-temperature treatment $\left(35 / 30{ }^{\circ} \mathrm{C}\right.$ day/night $)$ 
Table 1 Dry weight of leaves, stem, and root of Brassica oleracea var. italica exposed to control, low-temperature, and high-temperature treatment. Data are presented as mean \pm standard deviation and different letters in the same row indicate significant differences among treatment by one-way ANOVA followed by LSD test $(p<0.05)$

\begin{tabular}{cccc}
\hline \hline & Control & Low temperature High temperature \\
\hline Leaves $(\mathrm{g})$ & $76.6 \pm 15.0 \mathrm{a}$ & $46.9 \pm 4.27 \mathrm{a}$ & $45.7 \pm 14.6 \mathrm{a}$ \\
Stem $(\mathrm{g})$ & $50.2 \pm 4.94 \mathrm{a}$ & $48.6 \pm 11.4 \mathrm{a}$ & $53.8 \pm 14.4 \mathrm{a}$ \\
Root $(\mathrm{g})$ & $6.7 \pm 0.36 \mathrm{~b}$ & $9.0 \pm 2.66 \mathrm{ab}$ & $12.3 \pm 0.96 \mathrm{a}$ \\
\hline
\end{tabular}

고온 스트레스 하에서 Brassica oleracea var. italica의 반웅 상대습도가 $60 \%, 16$ 시간 광주기로 $35 / 30{ }^{\circ} \mathrm{C}$ (주간/야간)에 노출 시켜 고온 스트레스를 받은 Brassica oleracea var. italica의 $\mathrm{ECps}$ 와 sap flow rate는 정상적인 생육 조건의 ECps와 sap flow rate 보다 온도를 변경하면서 값이 증가하였다(Fig. 4). Lekas 등[19] 은 전나무와 가문비 줄기의 전기전도도가 광합성 유효광량자속 밀도와 온도가 증가함에 따라 증가하였다고 보고 하였다. 또한, 고온 스트레스를 받은 Carrizo citrange와 Cleopatra mandarin은 정상적인 생육조건보다 더 높은 기공 전도도와 증 산율을 보였다[20]. 따라서, 물 및 이온 수송의 증가와 관련이 있는 $\mathrm{ECps}$ 가 고온 생육 조건에 의해 증가된 것으로 판단된다. $\mathrm{ECps}$, sap flow rate, 대기 온도와 토양 온도를 제외한 상대습 도, $\mathrm{CO}_{2}$, 토양 수분, 토양 전기전도도는 정상적인 생육 조건 하 에서의 값과 큰 변화가 없었다. 토양 수분 및 토양 전기전도도 값은 관수를 하였을 때 급격히 증가하였다(Fig. 4).

고온 스트레스를 받은 잎의 엽록소 $\mathrm{a}$, 엽록소 $\mathrm{b}$ 의 함량은 정 상적인 생육조건과 비교하여 유의한 차이가 없었다(Fig. 3A). 고 온 스트레스를 받은 Arabidopsis thaliana L.에서는 엽록소 분 해의 첫 단계를 촉매하는 엽록소 분해 효소가 증가하여 잎의 엽록소를 클로로필리드(chlorophyllide)와 피톨(phytol)로 가수분 해하여 엽록소의 함량이 감소하였다[21]. 그러나 본 연구에서는 엽록소 함량에 유의한 차이가 없어 고온으로 인한 스트레스가 엽록소 함량에 반영이 안된 것으로 보이며 이는 고온에 노출시 킨 시간이 엽록소 함량에 영향을 미칠 만큼 충분히 길지 않았 기 때문인 것으로 판단된다. 고온에 노출된 Brassica oleracea var. italica 잎과 줄기의 건조 중량도 대조구와 유의한 차이가 없어 생육량에 차이를 미칠 만큼 스트레스 처리가 길지 않았던 것으로 판단된다(Table 1).

고온 스트레스를 받은 잎의 프롤린 함량은 정상적인 조건에 서 생육했을 때 보다 증가하였다(Fig. 3B). 프롤린은 스트레스 환경에서 삼투조절 외에도 산화 환원 균형 유지 및 라디칼 소 거, 분자 샤페론(molecular chaperone) 역할을 하는 단백질 고유 구조의 유지 등 다양한 효소의 활성을 강화하고 세포막 손상을 줄이는 데 기여하는 등 많은 다른 보호 효과를 나타낸다. 따라 서, 프롤린의 축적은 고온으로 인한 증산 속도의 증가 및 토양 가뭄으로 인한 수분 손실과 관련이 있다[20]. 본 연구에서는 고 온 스트레스 하에서 Brassica oleracea var. italica의 프롤린 함 량이 현저히 증가하여 고온으로 인한 스트레스를 받았다고 판 단된다.

본 연구에서는 온도 변화에 따른 식물의 반응을 모니터링하 기 위한 방법으로 ECps와 sap flow rate를 측정하였으며 외부 온도변화에 따라 식물의 양수분 이동이 즉각적으로 반응하여
$\mathrm{ECps}$ 의 값이 변화되는 것을 확인하였다. 그러나 sap flow rate 의 경우 저온과 고온 조건에서 온도 변화와 같은 패턴으로 값 이 변화하여 광합성과 증산에 따른 식물의 수액 이동을 제대로 반영하지 못한 것으로 판단된다. ECps가 식물의 스트레스를 잘 반영하는지 평가하기 위해 엽록소와 프롤린 함량, 건물중을 대 조구와 비교하였으며 건물중의 경우 처리 시간이 짧아 유의한 차이가 나타나지 않았으나 프롤린 함량의 변화로 식물의 스트 레스 여부를 확인할 수 있었다. 그러나 프롤린 함량은 파괴적 인 방법으로 분석이 가능하며, 분석 시간이 오래 걸리고 측정 법이 복잡하다. 그러나 식물 양수분 이동의 활성도를 보여주는 $\mathrm{ECps}$ 는 비파괴적으로 식물의 상태를 지속적으로 모니터링 할 수 있어 환경 조건의 변화에 따른 식물의 이상 반응을 빠르게 판단하고 스트레스 환경을 즉각적으로 개선하는데 적용할 수 있 다고 판단된다.

\section{초 록}

기상이변으로 인한 식물 스트레스를 평가하기 위해 토양과 식 물에 적용할 수 있는 여러 센서가 개발되었다. 따라서 본 연구 의 목적은 식물의 온도 스트레스를 평가하기 위해 다양한 센서 를 사용하여 기후 및 토양 상태와 식물 반응을 모니터링하는 것이다. 식물 반응을 평가하기 위한 식물 센서로 식물 줄기의 전기전도도, sap flow rate를 모니터링하였다. 식물 줄기의 전기 전도도는 물과 이온 수송을 포함한 식물의 생리적 활성을 반영 한다. 완전히 자란 Brassica oleracea var. italica를 온도 20/15 ${ }^{\circ} \mathrm{C}$ (낮/밤), 16 시간 광주기로 하여 대조구로 설정하였으며 저온 $15 / 10{ }^{\circ} \mathrm{C}$ 및 고온 $35 / 30{ }^{\circ} \mathrm{C}$ 에 노출시키면서 토양 및 식물 상태 를 모니터링하였다. 식물 줄기의 전기전도도, sap flow rate는 낮에는 증가하고 밤에는 감소하였다. 저온 스트레스 하에서 Brassica oleracea var. italica 줄기의 전기전도도는 대조구보다 낮았고, 고온 스트레스 하에서는 대조구보다 높아 물과 이온 수 송이 온도에 의해 영향을 받았음을 나타낸다. 그러나 엽록소 $\mathrm{a}$ 와 $\mathrm{b}$ 함량은 저온 스트레스를 받은 잎에서 증가했고 고온 스트 레스를 받은 잎에서는 대조구와 차이가 없었다. 잎의 프롤린 함 량은 저온 스트레스에서는 대조구와 차이가 없는 반면, 고온 스 트레스에서는 증가했다. 프롤린 합성은 환경 스트레스 하에서 식물의 방어 메커니즘으로 작용한다. 따라서 Brassica oleracea var. Italica는 저온보다 고온 스트레스에 더 민감한 것으로 판 단된다.

Keywords 식물 전기전도도 · 엽록소 · 온도 스트레스 · 토양 수분 · 프롤린 · Sap flow rate

감사의 글 본 논문은 농촌진흥청 연구사업(세부과제번호: PJ015050012020) 의 지원에 의해 이루어진 것임.

\section{References}

1. Alcázar R, Marco F, Cuevas JC, Patron M, Ferrando A, Carrasco P, Tiburcio AF, Altabella T (2006) Involvement of polyamines in plant response to abiotic stress. Biotechnol Lett 28: 1867-1876 
2. Krasensky J, Jonak C (2012) Drought, salt, and temperature stressinduced metabolic rearrangements and regulatory networks. J Exp Bot 63(4): 1593-1608

3. Agrios GN (2005) Plant Pathology 5th Edition: Elsevier Academic Press. Burlington 79-103

4. Ábrahám E, Hourton-Cabassa C, Erdei L, Szabados L (2010) Methods for determination of proline in plants. In Plant Stress Tolerance (pp. 317 331). Humana Press

5. Ehret D, Lau A, Bittman S, Lin W, Shelford T (2001) Automated monitoring of greenhouse crops. agronomie, EDP Sciences, 21(4): 403 414

6. Repo T (1988) Physical and physiological aspects of impedance measurements in plants. Silva Fennica, 22(3): 181-193

7. Park HJ, Park JH, Park K, Ahn TI, Son JE (2018) Nondestructive measurement of paprika (Capsicum annuum L.) internal electrical conductivity and its relation to environmental factors. Horticultural Science and Technology 36: 691-701

8. Smith DM, Allen SJ (1996) Measurement of sap flow in plant stems. J Exp Bot 47(12): 1833-1844

9. Maclachlan S, Zalik S (1963) Plastid structure, chlorophyll concentration, and free amino acid composition of a chlorophyll mutant of barley. Canadian Journal of Botany 41(7): 1053-1062

10. Bates LS, Waldren RP, Teare ID (1973) Rapid determination of free proline for water-stress studies. Plant and Soil 39(1): 205-207

11. Xin X, Zhang W, Li Q (2018) Thermal methods for measuring the sap flow of common camellia. Forest Res Eng Int J 2(2): 87-94

12. Repo T, Zhang MIN, Ryyppö A, Vapaavuori E, Sutinen S (1994) Effects of freeze-thaw injury on parameters of distributed electrical circuits of stems and needles of Scots pine seedlings at different stages of acclimation. J Exp Bot 45(6): 823-833

13. Wan X, Landhäusser SM, Zwiazek JJ, Lieffers VJ (2004) Stomatal conductance and xylem sap properties of aspen (Populus tremuloides) in response to low soil temperature. Physiol Plant 122(1): 79-85

14. Tewari AK, Tripathy BC (1998) Temperature-stress-induced impairment of chlorophyll biosynthetic reactions in cucumber and wheat. Plant Physiology 117(3): 851-858

15. Markhart AH, Fiscus EL, Naylor AW, Kramer PJ (1979) Effect of temperature on water and ion transport in soybean and broccoli systems. Plant Physiology 64(1): 83-87

16. Chu T, Aspinall D, Paleg LG (1974) Stress metabolism. VI.* Temperature stress and the accumulation of proline in barley and radish. Funct Plant Biol 1(1): 87-97

17. Benko B (1969) The content of some amino acids in young apple shoots in relation to frost resistance. Biologia Plantarum 11(5): 334

18. Chu TM, Jusaitis M, Aspinall D, Paleg LG (1978) Accumulation of free proline at low temperatures. Physiol Plant 43(3): 254-260

19. Lekas TM, MacDougall RG, MacLean DA, Thompson RG (1990) Seasonal trends and effects of temperature and rainfall on stem electrical capacitance of spruce and fir trees. Canadian Journal of Forest Research 20(7): 970-977

20. Zandalinas SI, Rivero RM, Martínez V, Gómez-Cadenas A, Arbona V (2016) Tolerance of citrus plants to the combination of high temperatures and drought is associated to the increase in transpiration modulated by a reduction in abscisic acid levels. BMC plant biology 16(1): 105

21. Todorov DT, Karanov EN, Smith AR, Hall MA (2003) Chlorophyllase activity and chlorophyll content in wild type and eti 5 mutant of Arabidopsis thaliana subjected to low and high temperatures. Biologia plantarum 46(4): 633-636 